\title{
Simultaneous changes in anthocyanin, chlorophyll, and carotenoid contents produce green variegation in pink-leaved ornamental kale
}

Yang Liu ${ }^{1,2}$, Xin Feng ${ }^{1,2}$, Yuting Zhang ${ }^{1,2}$, Fuhui Zhou ${ }^{1,2}$ and Pengfang Zhu ${ }^{1,2^{*}}$

\begin{abstract}
Background: Anthocyanin, chlorophyll, and carotenoid pigments are widely distributed in plants, producing various colors. Ornamental kale (Brassica oleracea var. acephala DC) which has colorful inner leaves is an ideal plant to explore how these three pigments contribute to leaf color. The molecular mechanisms of the coloration in ornamental kale could provide reference for exploring the mechanisms of pigmentation in other plants.

Results: In this study, we sequenced the transcriptome and determined the pigment contents of an unusual cultivar of ornamental kale with three different types of leaf coloration: pink (C3), light pink (C2), and variegated pink-green (C1). A total of 23,965 differentially expressed genes were detected in pairwise comparisons among the three types of leaves. The results indicate that Bo9g058630 coding dihydroflavonol 4-reductase (DFR) and Bo3g019080 coding shikimate O-hydroxycinnamoyltransferase (HCT) acted in anthocyanin biosynthesis in pink leaves. Bo1g053420 coding pheophorbidase (PPD) and Bo3g012430 coding 15-cis-phytoene synthase (crtB) were identified as candidate genes for chlorophyll metabolism and carotenoid biosynthesis, respectively. The transcription factors TT8, MYBL2, GATA21, GLK2, and RR1 might participate in triggering the leaf color change in ornamental kale. Anthocyanin content was highest in C3 and lowest in C1. Chlorophyll and carotenoid contents were lowest in C2 and highest in C1.

Conclusions: Based on these findings, we suspected that the decrease in anthocyanin biosynthesis and the increase in chlorophyll and carotenoid biosynthesis might be the reason for the leaf changing from pink to variegate pink-green in this unusual cultivar. Our research provides insight into the molecular mechanisms of leaf coloration in ornamental kale, contributing to a theoretical foundation for breeding new varieties.
\end{abstract}

Keywords: Anthocyanin, Carotenoids, Chlorophyll, Leaf color, Ornamental kale, Transcriptome analysis, Variegated leaf

\footnotetext{
* Correspondence: pengfangzhu@syau.edu.cn

'College of Forestry, Shenyang Agricultural University, Shenyang 110866,

China

${ }^{2}$ Key Laboratory of Forest Tree Genetics, Breeding and Cultivation of Liaoning Province, Shenyang 110866, China
}

(c) The Author(s). 2021 Open Access This article is licensed under a Creative Commons Attribution 4.0 International License, which permits use, sharing, adaptation, distribution and reproduction in any medium or format, as long as you give appropriate credit to the original author(s) and the source, provide a link to the Creative Commons licence, and indicate if changes were made. The images or other third party material in this article are included in the article's Creative Commons licence, unless indicated otherwise in a credit line to the material. If material is not included in the article's Creative Commons licence and your intended use is not permitted by statutory regulation or exceeds the permitted use, you will need to obtain permission directly from the copyright holder. To view a copy of this licence, visit http://creativecommons.org/licenses/by/4.0/ The Creative Commons Public Domain Dedication waiver (http://creativecommons.org/publicdomain/zero/1.0/) applies to the data made available in this article, unless otherwise stated in a credit line to the data. 


\section{Background}

The wide variety of colors displayed by plant leaves, flowers, and fruits are mainly produced by combinations of three types of pigments: anthocyanins, chlorophyll, and carotenoids. Anthocyanins are water-soluble and widely present in plant vacuoles [1]. Depending on the types and amounts of anthocyanins present, plant tissues can appear purple, red, pink, or blue in color. Anthocyanins also act as antioxidants [2]. Chlorophylls are the main photosynthetic pigments in plants; the main types are chlorophyll $a$, which is blue-green, and chlorophyll $b$, which is yellow-green under light conditions [3]. Carotenoids are also photosynthetic pigments, and help to protect the photosynthetic apparatus from photo-oxidation [4]. Depending on the distribution of carotenoids, plants can appear yellow, orange, or red.

In plants, the anthocyanin biosynthetic pathway is well understood $[5,6]$. Comparative transcriptome analysis of purple potato (Solanum tuberosum) revealed several structural genes involved in anthocyanin biosynthesis, such as those encoding phenylalanine ammonia-lyase (PAL), chalcone synthase (CHS), dihydroflavonol 4-reductase (DFR), and anthocyanin synthase (ANS) [7]. A light-induced $M Y B$ gene regulates anthocyanin biosynthesis in red apples (Malus domestica Borch) [8]. Chromatin immunoprecipitation analysis revealed that PIF3 and HY5 simultaneously regulate anthocyanin biosynthesis in Arabidopsis thaliana [9].

Chlorophyll biosynthesis and chloroplast development are well studied in rice (Oryza sativa) [10], Brassica rapa [11], Brassica oleracea [12], A. thaliana [13, 14], and other plants. Fine mapping revealed that OsHemA is essential for chlorophyll biosynthesis in rice [15]. Mapbased cloning and sequencing of the FLU gene suggests that $F L U$ is a negative regulator of chlorophyll biosynthesis in A. thaliana [16].

The carotenoid biosynthetic pathway is also well understood [17]. Carotenoids are produced by two independent pathways: the 2-C-methyl-D-erythritol-4phosphate (MEP) pathway in plastids, and the mevalonate (MVA) pathway in the cytosol [18]. Under dark conditions, upregulation of PSY (phytoene synthase) leads to increased carotenoid content in $A$. thaliana [19]. CRTISO, encoding carotenoid isomerase, and $\varepsilon-$ $L C Y$, encoding epsilon lycopene cyclase, are two core genes related to specific orange pigmentation in $L$. tulipifera [20]. In Brassica campestris, LCYE, LCYE2, CCD, and $Z D S$ were upregulated in yellow leaves relative to dark green leaves [18]. Br-or was identified as regulator of carotenoid biosynthesis in $B$. rapa [21]. $\operatorname{crt} B$, encoding Erwinia uredovora phytoene synthase, is important in the accumulation of carotenoids in tomato fruits. Overexpression of $\operatorname{crtB}$ resulted in a significant increase in carotenoid content in tomato fruits [22].
Ornamental kale (Brassica oleracea var. acephala DC.), a horticultural variety, is a biennial foliage herb with leaves of various shapes and colors. Leaf color is a key commercial trait of ornamental kale [23]. At the rosette stage, the inner leaves appear purple, red, pink, light pink, white, or other colors, while the outer leaves are deep purple or green [24]. Anthocyanins, chlorophylls, and carotenoids are the most important pigments determining leaf color in ornamental kale. Cyanidin was the main type of anthocyanin in purple leaves of ornamental kale, while no anthocyanin was detected in white-leaved cultivars [25]. Fine mapping revealed that Bo9g058680 controls red and purple leaf phenotypes in ornamental kale [26, 27]. Regulatory factors related to anthocyanin biosynthesis in $B$. oleracea have been identified using RNA sequencing (RNA-seq). MYB, bHLH, and WD40 transcription factors are essential for regulating anthocyanin biosynthesis; R2R3-MYB, BoTTG1, BoTT8, $B o M Y B L 2$, and BoTT19 are particularly important for anthocyanin biosynthesis in ornamental kale [28]. Structural genes such as $C 4 H, T I R 1$, and $L B D 39$, and transcription factors such as NAC and WRKY, related to anthocyanin biosynthesis in a bicolor ornamental kale with green margins and red centers, were identified using RNA-seq [29]. A comparison of the transcriptomes of purple and white ornamental kales identified BoC4H2, BoUGT9, and BoGST21 as candidate genes involved in the anthocyanin biosynthetic pathway, and six unigenes, BoHEMA1, BoCRD1, BoPORC1, BoPORC2, BoCAO, and BoCLH1, as related to chlorophyll metabolism [30]. RNA-seq indicated that the inhibition of chlorophyll biosynthesis probably led to the change in leaf color from green to white in ornamental kale [24].

In this study, we analyzed the molecular mechanism of leaf color change in a triple color ornamental kale cultivar. We identified differentially expressed genes (DEGs) involved in the biosynthesis of anthocyanin and carotenoid, and chlorophyll metabolism through RNA-seq. Pigment contents of the leaves of three different colors were also evaluated. Our results provide insight into the molecular mechanisms of leaf color in ornamental kale, and a reference for exploring the mechanisms of pigmentation in other plants.

\section{Results}

\section{RNA sequencing and sequence assembly}

We have identified an unusual ornamental kale with three different colored leaves (Fig. 1A). The outer leaves are variegated pink-green (Fig. 1B), the middle are light pink (Fig. 1C) and the inner are pink (Fig. 1D) in color. To characterize the differences in gene expression among kale leaves of three different colors $(\mathrm{C} 1, \mathrm{C} 2$, and C3), we constructed cDNA libraries from each leaf type 


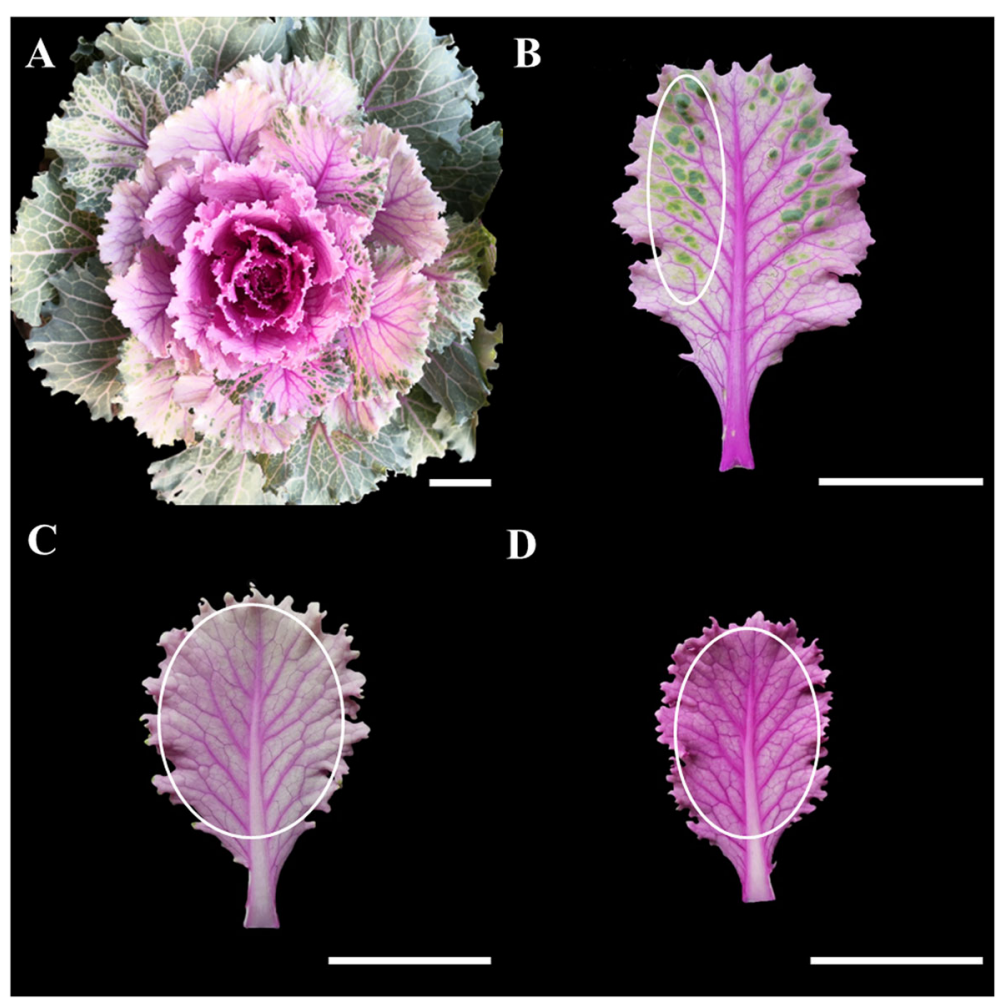

Fig. 1 Phenotype and sampled tissues of 'Pink 42'. A The phenotype of 'Pink 42'. At young stage, leaves are pink, turning into light pink and then variegated pink-green color appears as they developed further. B A variegated pink-green leaf of 'Pink 42', designated as C1. C A light pink leaf of 'Pink 42', designated as C2. D A pink leaf of 'Pink 42', designated as C3. White circles indicate the sampling sites

for sequencing. We obtained 413 million raw reads, which were filtered with fastp (https://github.com/ OpenGene/fastp) (Table 1) [31]. After removing the reads containing joints, with unknown bases $N>10 \%$ and low quality, a total of 404 million clean reads were obtained. More than $93 \%$ of reads had an average quality score $>30$ (Q30 score), and the clean reads ratio was around $98 \%$, indicating that the sequencing data were accurate and reliable for further analysis.

\section{Identification and analysis of DEGs}

DEGs were filtered under a fold-change of more than 2, and a corrected $P$-value $\leq 0.05$, according to DESeq2 [32]. A total of 23,965 DEGs were identified in three comparison groups $(\mathrm{C} 1$ versus $\mathrm{C} 2, \mathrm{C} 1$ versus $\mathrm{C} 3$, and $\mathrm{C} 2$ versus $\mathrm{C} 3$ ). Eight thousand fourteen DEGs were detected in the $\mathrm{C} 2$ versus $\mathrm{C} 3$ comparison, including 3628 upregulated genes and 4386 downregulated genes (Fig. 2A). Five thousand two hundred eighteen DEGs were

Table 1 Reads quality control and comparison of clean reads with the reference genome

\begin{tabular}{llllllll}
\hline Sample & $\begin{array}{l}\text { Total Raw Reads } \\
\text { (M) }\end{array}$ & $\begin{array}{l}\text { Total Clean Reads } \\
(\mathbf{M})\end{array}$ & $\begin{array}{l}\text { Total Clean Base } \\
(\mathbf{G b})\end{array}$ & $\begin{array}{l}\text { Q30 } \\
(\%)\end{array}$ & $\begin{array}{l}\text { Clean Reads Ratio } \\
(\%)\end{array}$ & $\begin{array}{l}\text { Total Mapping } \\
(\%)\end{array}$ & $\begin{array}{l}\text { Uniquely Mapping } \\
(\%)\end{array}$ \\
\hline C1_1 & 47.74 & 46.57 & 6.88 & 94.88 & 97.53 & 90.48 & 86.52 \\
C1_2 & 45.18 & 44.13 & 6.54 & 95.12 & 97.68 & 91.12 & 86.82 \\
C1_3 & 47.63 & 46.64 & 6.92 & 94.5 & 97.92 & 90.84 & 87.27 \\
C2_1 & 48.93 & 47.82 & 7.08 & 94.79 & 97.73 & 88.89 & 84.48 \\
C2_2 & 42.53 & 41.51 & 6.14 & 94.69 & 97.6 & 89.66 & 83.85 \\
C2_3 & 43.71 & 42.77 & 6.36 & 93.93 & 97.85 & 88.51 & 85.67 \\
C3_1 & 46.49 & 45.6 & 6.78 & 94.9 & 98.09 & 90.42 & 86.9 \\
C3_2 & 43.65 & 42.85 & 6.36 & 94.9 & 98.17 & 90.22 & 86.73 \\
C3_3 & 47.37 & 46.32 & 6.81 & 94.91 & 97.78 & 90.08 & 86.79 \\
\hline
\end{tabular}



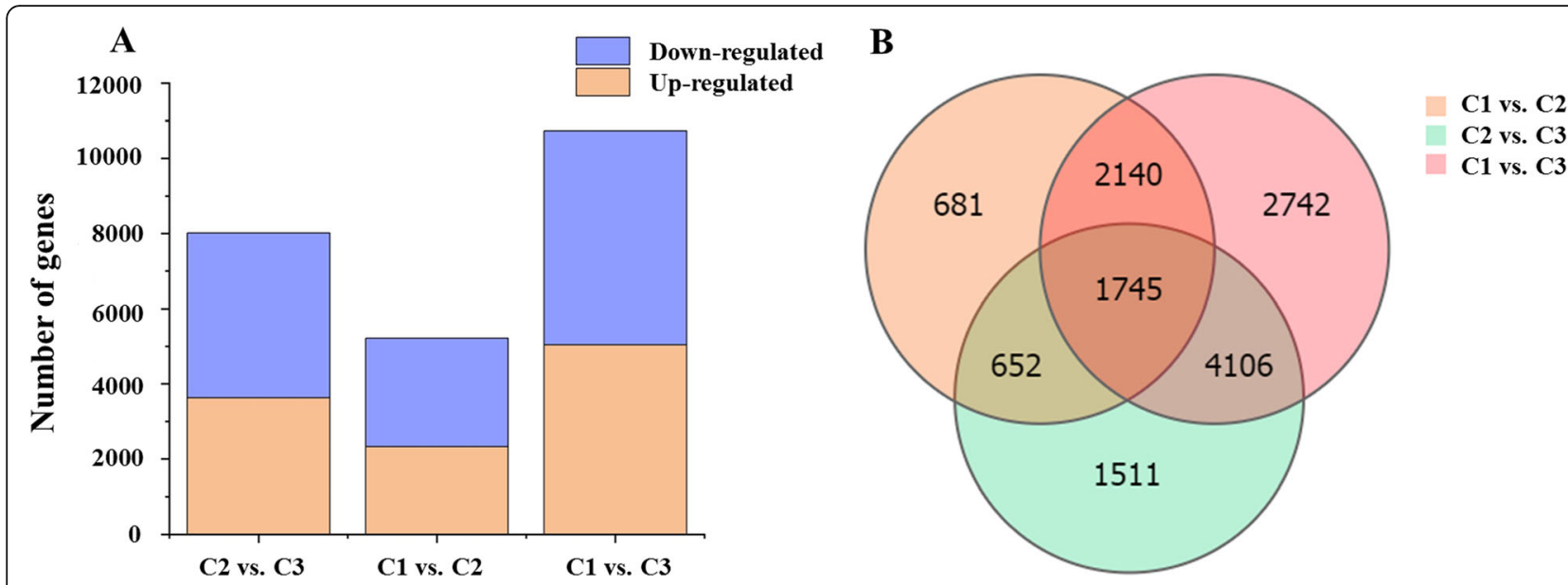

Fig. 2 The number of differentially expressed genes (DEGs) detected in comparisons of different colored leaves of 'Pink 42'. A The number of upregulated and downregulated DEGs in pairwise comparisons of variegated pink-green (C1), light pink (C2), and pink (C3) leaves. B Venn diagram analysis of DEGs in the pairwise comparisons

detected in the $\mathrm{C} 1$ versus $\mathrm{C} 2$ comparison, including 2327 upregulated genes and 2891 downregulated genes. There were 10,733 DEGs in the C1 versus C3 comparison, including 5040 upregulated genes and 5693 downregulated genes. As shown in the Venn diagram, there were seven groups present (Fig. 2B). There were 1745 DEGs common to the $C 1$ versus $C 2, C 1$ versus $C 3$, and $\mathrm{C} 2$ versus $\mathrm{C} 3$ comparisons. Two thousand one hundred forty DEGs were common to the $\mathrm{C} 1$ versus $\mathrm{C} 2$ and $\mathrm{C} 1$ versus C3 comparisons. Six hundred fifty-two DEGs were common to the $\mathrm{C} 1$ versus $\mathrm{C} 2$ and $\mathrm{C} 2$ versus $\mathrm{C} 3$ comparisons. Four thousand one hundred sixty DEGs were common to the $\mathrm{C} 1$ versus $\mathrm{C} 3$ and $\mathrm{C} 2$ versus $\mathrm{C} 3$ comparisons.

\section{Gene ontology (GO) annotation and DEG enrichment analysis} Using Gene Ontology (GO), differentially expressed genes in the three comparisons were classified into three categories: molecular function, cellular component, and biological process. In the $\mathrm{C} 2$ versus $\mathrm{C} 3$ comparison, 8014 DEGs were classified into 43 GO terms. Of these, 20 belonged to biological process, 11 to cellular component, and 12 to molecular function. 'Binding' was the most often enriched term (Fig. 3A). In the $\mathrm{C} 1$ versus $\mathrm{C} 2$ comparison, 5218 DEGs were classified into 41 GO terms. Of these, 18 belonged to biological process, 11 to cellular component, and 12 to molecular function. 'Metabolic process' was the most often enriched term (Fig. 3B). In the $\mathrm{C} 1$ versus C3 comparison, 10,733 DEGs were classified into $43 \mathrm{GO}$ terms. Of these, 20 belonged to biological process, 11 terms to cellular component, and 12 to molecular function. "Metabolic process" was the most enriched term (Fig. 3C). The top five enriched terms were 'metabolic process', 'catalytic activity', 'binding', 'cellular process', and 'single-organism process'.

\section{Kyoto encyclopedia of genes and genomes (KEGG)} pathway enrichment analysis of the DEGs

We performed Kyoto Encyclopedia of Genes and Genomes (KEGG) pathway enrichment analysis of the DEGs using the $\mathrm{R}$ package. In the $\mathrm{C} 2$ versus $\mathrm{C} 3$ comparison, 'photosynthesis', 'mismatch repair', 'photosynthesis-antenna proteins', 'fanconi anemia pathway', 'nucleotide excision repair', and 'homologous recombination' were the most significantly enriched pathways (Fig. 4A). In the $\mathrm{C} 1$ versus $\mathrm{C} 2$ comparison, 'ribosome', 'photosynthesis', 'carbon fixation in photosynthetic organisms', 'glyoxylate and dicarboxylate metabolism', 'porphyrin and chlorophyll metabolism', and 'carotenoid biosynthesis' were the most significantly enriched pathways (Fig. 4B). The six most significantly enriched pathways in the $\mathrm{C} 1$ versus $\mathrm{C} 3$ comparison were 'ribosome', 'nucleotide excision repair', 'fanconi anemia pathway', 'mismatch repair', 'photosynthesis', and 'homologous recombination' (Fig. 4C).

\section{Expression patterns of DEGS involved in anthocyanin biosynthesis}

Across the three comparisons of leaf colors, 15 DEGs related to anthocyanin biosynthesis were detected. Ten anthocyanin biosynthesis-related DEGs were detected in the $\mathrm{C} 2$ versus $\mathrm{C} 3$ comparison (Fig. $5 \mathrm{~A}$ ). Nine genes were upregulated in C3 compared with C2: PAL (Bo8g082620), 4CL (Bo6g099190), C4H (Bo4g173080), CHS (Bo9g166290), CHI (Bo6g068550), F3'H (Bo9g174880), F3H (Bo8g081770), DFR (Bo9g058630), and ANS (Bo7g108300), and one gene, HCT (Bo3g019080), was downregulated. Of these, C4H (Bo4g173080) showed the most extreme difference in expression between C2 and C3. PAL (Bo5g137560), 4CL (Bo9g076260), and F3'H (Bo9g174900), which are involved in the early steps of anthocyanin biosynthesis, were 

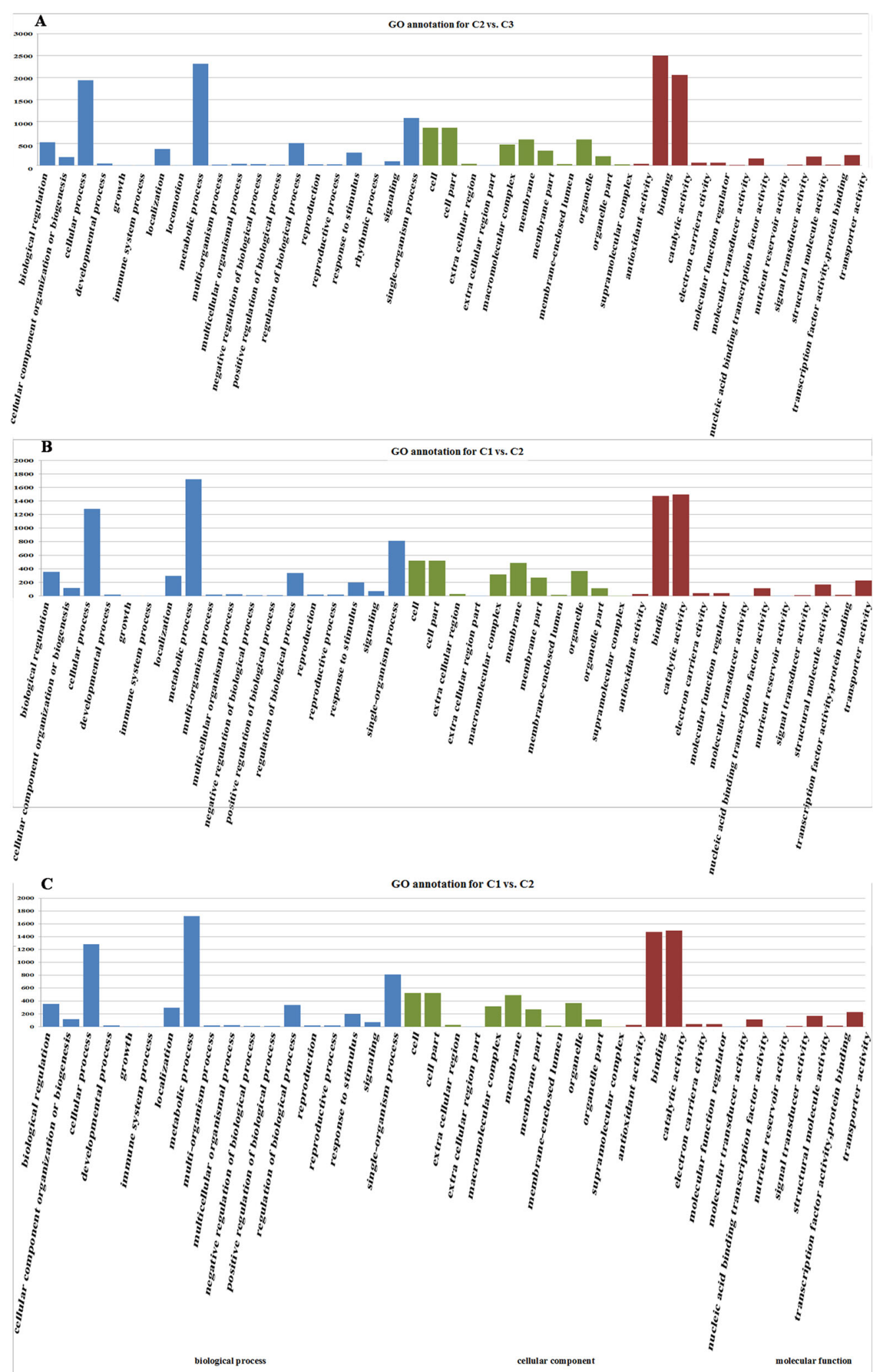

Fig. 3 Gene Ontology (GO) annotation of differentially expressed genes (DEGs) detected in comparisons of different colored leaves of 'Pink 42'. A GO annotation of DEGs detected in the C2 versus C3 comparisons. B GO annotation of DEGs detected in the C1 versus C2 comparisons. C GO annotation of DEGs detected in the C1 versus C3 comparisons 


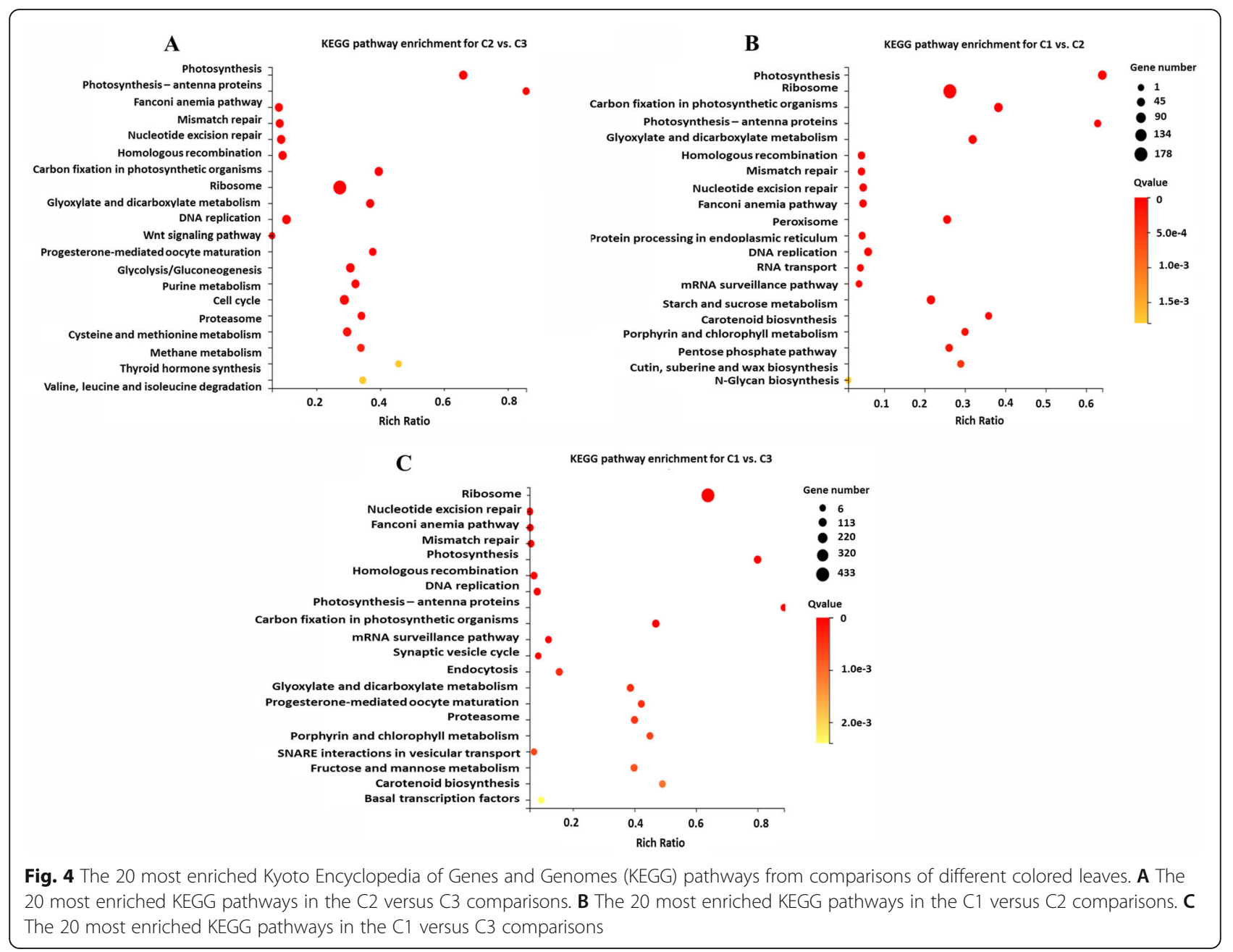

upregulated in variegated pink-green leaves $(\mathrm{C} 1)$ compared with light pink leaves (C2) (Fig. 5B). F3'H (Bo9g174900) showed the biggest difference in expression in this comparison. There were 10 DEGs related to anthocyanin biosynthesis in the $\mathrm{C} 1$ versus C3 comparison: PAL (Bo6g067250), 4CL (Bo5g102350), C4H (Bo4g173070), HCT (Bo3g019080), CHS (Bo9g166290), CHI (Bo8g088480), F3'H (Bo9g174880), F3H (Bo8g081770), DFR (Bo9g058630), and ANS (Bo7g10 8300) (Fig. 5C). All of these genes, except for $\mathrm{C} 4 \mathrm{H}$ and $H C T$, were upregulated in $\mathrm{C} 3$ compared with $\mathrm{C} 1$. Of these DEGs, DFR (Bo9g058630) showed the highest expression in pink leaves (C3) compared with variegated pink-green leaves.

\section{Expression patterns of DEGs related to chlorophyll metabolism}

Two DEGs related to chlorophyll biosynthesis (CPOX, Bo8g116050; ChlH, Bo5g009050), two related to the chlorophyll cycle (CAO, Bo8g021880; NOL, Bo8g033750), and two related to chlorophyll degradation ( $P P D$, Bo1g053420; RCCR, Bo1g005060) were detected in the C2 versus C3 comparison (Fig. 6A). All of these DEGs were upregulated in light pink leaves $(\mathrm{C} 2)$ compared with pink leaves (C3). Of these DEGs, PPD (Bo1g053420) showed the highest relative expression level in light pink leaves. In the $\mathrm{C} 1$ versus $\mathrm{C} 2$ comparison, six DEGs involved in chlorophyll biosynthesis (HemA, Bo9g050950; HemN, Bo9g017590; chlH, Bo3g009280; chlM, Bo7g109930; chlE, Bo6g072440; por, Bo1g049340), three involved in the chlorophyll cycle (CAO, Bo8g021880; NOL, Bo4g133190; HCAR, Bo5gO 04750), and two involved in chlorophyll degradation (PPD, Bo1g053420; PAO, Bo1g063840) were detected (Fig. 6B). All of these DEGs were upregulated in variegated pink-green leaves $(\mathrm{C} 1)$ relative to light pink leaves $(\mathrm{C} 2)$. Compared with C2, PPD (Bo1g053420) showed the highest expression in variegated pink-green leaves $(C 1)$. In the $C 1$ versus $C 3$ comparison, we detected nine DEGs related to chlorophyll biosynthesis (HemD, Bo8g098680; HemE, Bo5g127600; HemY, Bo5g003060; chlH, Bo7g106010; chlM, Bo7g109930; chlE, Bo8g091280; por, Bo8g002560; DVR, Bo9g154670; chlG, Bo1g058980), three involved in the chlorophyll cycle (CAO, Bo8g021880; NOL, Bo3g003030; HCAR, Bo5g0047 


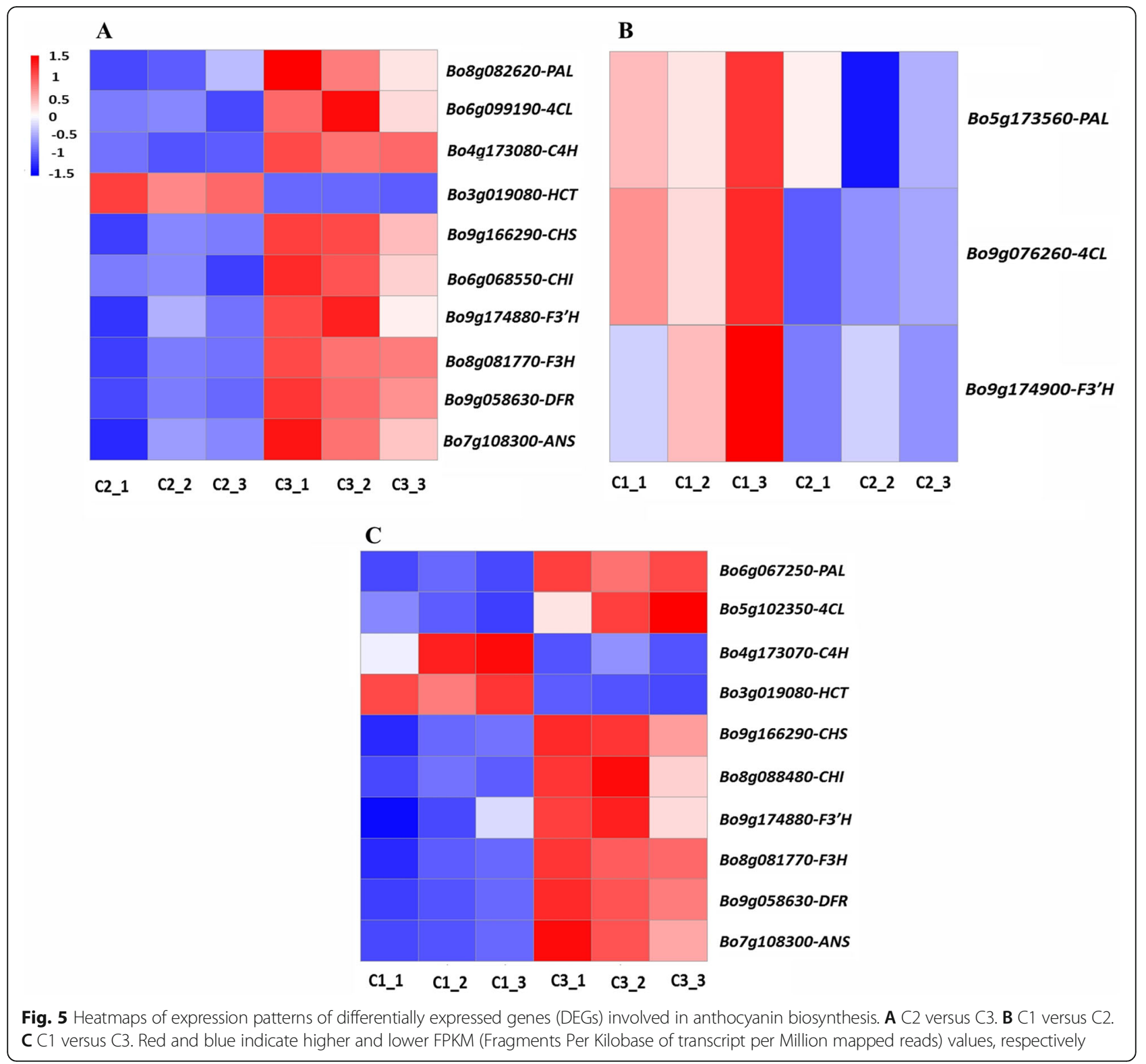

$50)$ and three involved in chlorophyll degradation $(P P D$, Bolg053420; PAO, Bolg063840; RCCR, Bolg005060) (Fig. $6 \mathrm{C})$. All of these DEGs were downregulated in pink leaves (C3) relative to variegated pink-green leaves (C1). Of these DEGs, PPD (Bo1g053420) showed the highest expression in $\mathrm{C} 1$ relative to $\mathrm{C} 3$.

\section{Expression patterns of DEGs related to carotenoid biosynthesis}

Three DEGs involved in carotenoid biosynthesis (ZEP, Bo7g064130; VDE, Bo5g009080; NCED, Bo5g130280) were detected in the $\mathrm{C} 2$ versus $\mathrm{C} 3$ comparison (Fig. 7A). All of these DEGs were upregulated in light pink leaves (C2) relative to pink leaves (C3). VDE (Bo5g009080) showed the highest expression in $\mathrm{C} 2$ compared to $\mathrm{C} 3$.
Eight DEGs involved in carotenoid biosynthesis ( $\operatorname{crtB}$, Bo3g012430; PDS, Bo4g127210; ZDS, Bo5g146930; lcyB, Bo5g137670; crtZ, Bo7g110490; ZEP, Bo7g064130; VDE, Bo5g009080; NCED, Bo3g066190) were detected in the $\mathrm{C} 1$ versus $\mathrm{C} 2$ comparison (Fig. $7 \mathrm{~B}$ ). All of these DEGs were upregulated in variegated pink-green leaves $(\mathrm{C} 1)$ relative to light pink leaves (C2). crtB (Bo3g012430) showed the biggest difference in expression in this comparison. In the $\mathrm{C} 1$ versus $\mathrm{C} 3$ comparison, we detected nine DEGs involved in carotenoid biosynthesis ( $\operatorname{crtB}$, Bo3g012430; PDS, Bo4g127210; ZDS, Bo5g146930; crtH, Bo8g114430; lcyB, Bo5g137670; crtZ, Bo7g110490; ZEP, Bo7g064130; VDE, Bo5g009080; NCED, Bo3g066190) (Fig. 7C). All of these DEGs were upregulated in variegated pink-green leaves $(\mathrm{C} 1)$ compared to pink leaves $(\mathrm{C} 3)$. 


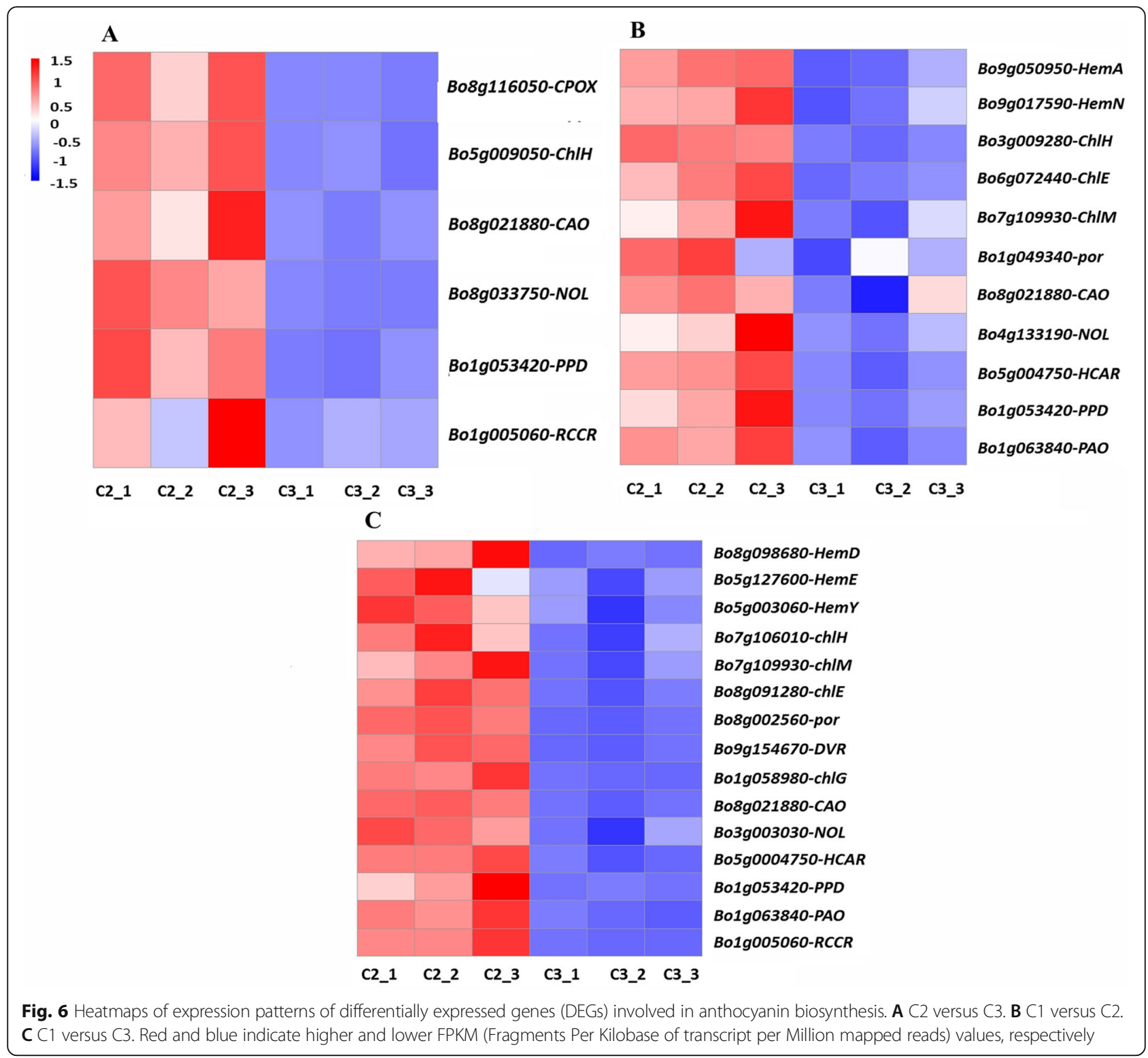

Identification and expression patterns of DEGs encoding transcription factors (TFs)

Transcription factors (TFs) were identified by aligning the DEGs to a plant TF database with BLASTX (http:// planttfdb.cbi.pku.edu.cn/). Four hundred eighty-three TFs including $102 \mathrm{MYB}, 62 \mathrm{bHLH}$, and 45 WD40 TFs were identified in the $\mathrm{C} 2$ versus $\mathrm{C} 3$ comparison (Additional file 1: Table S1). MYB12 (Bo4g004500), MYB113 (Bo9g100940), MYB113 (Bo9g099880), MYB3 (Bo7g057770), MYB48 (Bo3g130340), and MYBL2 (Bo2g070770) were annotated as involved in the regulation of anthocyanin biosynthesis. $M Y B 12$ and MYBL2 showed the most extreme difference in expression between C2 and C3. MYB12 (Bo4g004500) was upregulated in C3, while MYBL2 (Bo2g070770) upregulated in $\mathrm{C} 2$. Among the $b H L H$ genes, four were annotated as involved in the regulation of anthocyanin biosynthesis: EGL3 (Bo9g035460), EGL3 (Bo9g029230), GL3 (Bo4g141990), and TT8 (Bo9g086910). In addition, we identified seven TFs involved in the regulation of chlorophyll metabolism, including two bZIP genes (ABF4, Bo3g073080; ABF4, Bo1g114840), two C2C2-GATA genes (GATA21, Bo9g127360; GATA21, Bo3g019610), two ARR-B genes (GLK3, Bo7g003410; GLK2, Bo7g067200), and one bHLH gene (PIL5, Bo7g003890). GLK2 (Bo7g067200) showed the most extreme difference in expression between $\mathrm{C} 2$ and $\mathrm{C} 3$.

There are 159 TFs including 37 MYBs, 49 bHLHs, and 18 WD40s in the $\mathrm{C} 1$ versus $\mathrm{C} 2$ comparison (Additional file 1: Table S2). Four bHLH genes (TT8, Bo9g086910; MYC4, Bo1g017990; MYC3, Bo7g075710; MYC2, Bo5 g086990) were annotated as involved in the regulation of 


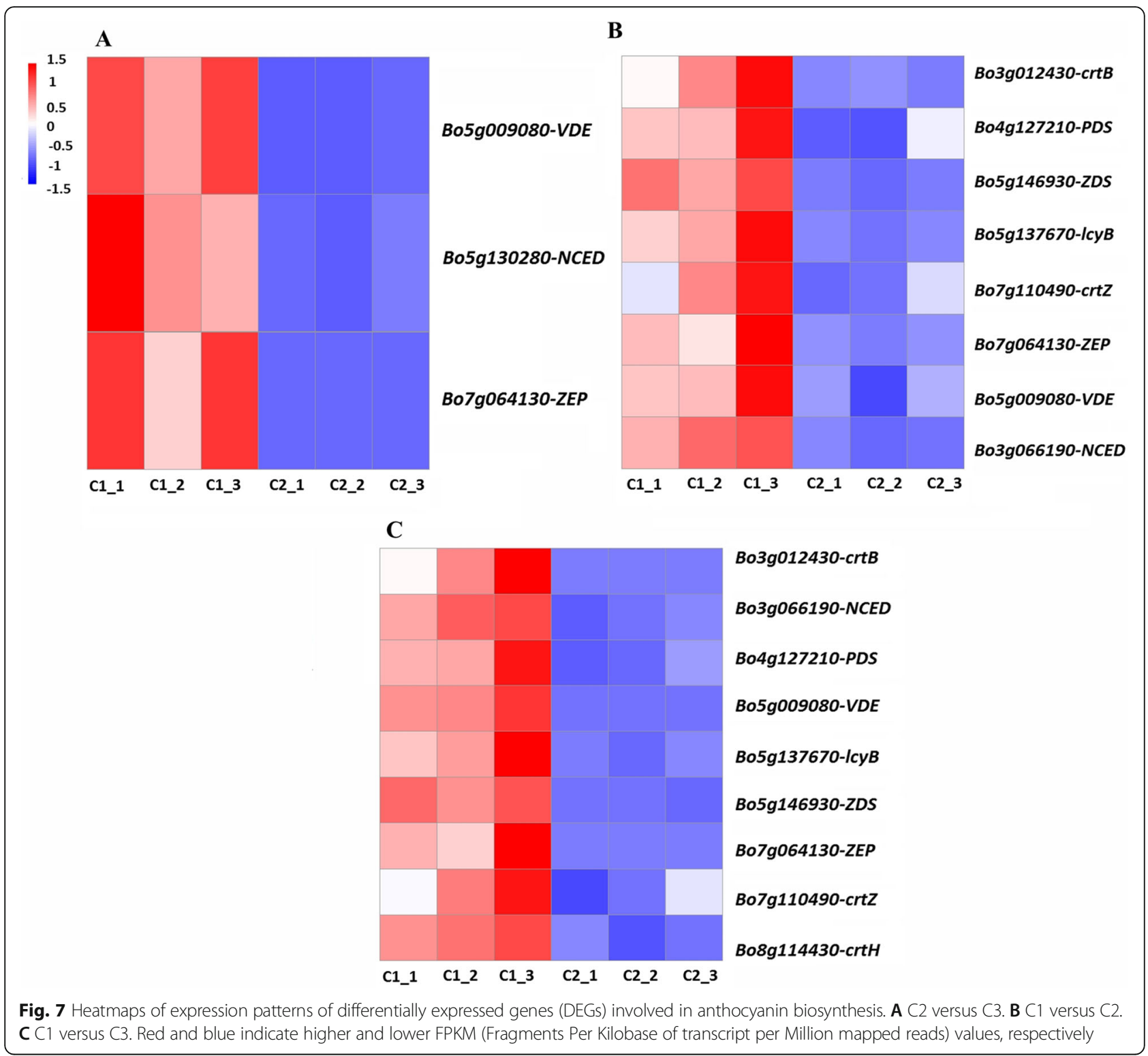

anthocyanin biosynthesis. The gene TT8 showed the most extreme difference in expression between $\mathrm{C} 1$ and $\mathrm{C} 2$. Two genes encoding C2C2-GATA TFs were detected in the $\mathrm{C} 1$ versus $\mathrm{C} 2$ comparison (GATA21, Bo2g033970; GATA22, Bo1g042950). The gene GATA22 showed the most extreme difference in expression between $\mathrm{C} 1$ and C2. Interestingly, the gene RR1 (Bo3g068530) identified in this comparison was not only involved in the regulation of anthocyanin biosynthesis but also in the regulation of chlorophyll metabolism. Its expression was highest in C2 compared with both $\mathrm{C} 3$ and $\mathrm{C} 1$.

\section{Quantitative real-time PCR (qRT-PCR) analysis of candidate genes}

Nine DEGs encoding structural genes and nine DEGs encoding regulatory genes were selected for qRT-PCR test.
The results confirmed that the selected genes were differentially expressed in three different colored leaves. Moreover, the most genes involved in anthocyanin biosynthesis were downregulated, while the genes involved in chlorophyll metabolism and carotenoid biosynthesis were upregulated in the transition from pink leaf to variegated pink-green leaf. It was coincided with the results obtained through RNAseq. The gene DFR (Bo9g058630), involved in anthocyanin biosynthesis, was not only downregulated during the pink leaf (C3) changing into variegated pink-green (C1) but also showed a biggest difference between $\mathrm{C} 3$ and $\mathrm{C} 1$. The gene HCT (Bo3g019080) which involved in anthocyanin biosynthesis in a reverse way was upregulated from $\mathrm{C} 3$ to C1. In addition, the genes CAO (Bo8g021880) and PPD (Bo1g053420), which involved in chlorophyll metabolism, and genes crtB (Bo3g012430), VDE (Bo5g009080) and ZEP 
(Bo7g064130), which involved in carotenoid biosynthesis, were all upregulated from $\mathrm{C} 3$ to $\mathrm{C} 1$ (Fig. 8). The genes EGL3 (Bo9g035460), TT8 (Bo9g086910), MYB113 (Bo6g10 0940) and MYB12 (Bo4g004500), positively regulating anthocyanin biosynthesis, were downregulated from $\mathrm{C} 3$ stage to C1 stage (Fig. 9). MYBL2 (Bo2g070770), a gene negatively regulating anthocyanin biosynthesis, was upregulated from $\mathrm{C} 3$ stage to $\mathrm{C} 1$ stage. The expression of gene RR1 (Bo3g068530) was highest at C2 stage. The fold change of genes expression regulating anthocyanin biosynthesis was larger in $\mathrm{C} 2$ versus $\mathrm{C} 3$ than $\mathrm{C} 1$ versus $\mathrm{C} 2$ comparison. Instead, the fold change of genes expression regulating chlorophyll biosynthesis was larger in $\mathrm{C} 1$ versus $\mathrm{C} 2$ than $\mathrm{C} 2$ versus $\mathrm{C} 3$ comparison (Fig. 9).

\section{Anthocyanin, chlorophyll, and carotenoid contents in three different colored leaves}

We quantified anthocyanin, chlorophyll, and carotenoid contents in leaves of three different colors. The contents of anthocyanin, chlorophyll, and carotenoid in C3 were
$0.3555 \mathrm{mg} \cdot \mathrm{g}^{-1}$ (fresh weight; FW), $0.0189 \mathrm{mg} \cdot \mathrm{g}^{-1}(\mathrm{FW})$, and $0.0150 \mathrm{mg} \cdot \mathrm{g}^{-1}$ (FW), respectively. C2 leaves had 0.0988 $\mathrm{mg} \cdot \mathrm{g}^{-1}$ (FW) anthocyanin, $0.0158 \mathrm{mg} \cdot \mathrm{g}^{-1}$ (FW) chlorophyll, and $0.0012 \mathrm{mg} \cdot \mathrm{g}^{-1}$ (FW) carotenoid. The contents of anthocyanin, chlorophyll, and carotenoid in $\mathrm{C} 1$ were $0.0755 \mathrm{mg} \cdot \mathrm{g}^{-1}$ (FW), $0.3148 \mathrm{mg} \cdot \mathrm{g}^{-1}$ (FW), and 0.0318 $\mathrm{mg} \cdot \mathrm{g}^{-1}$ (FW), respectively. These results showed that pink leaves had the highest anthocyanin content. Chlorophyll and carotenoid contents were lowest in the light pink leaves. Chlorophyll and carotenoid contents were highest and anthocyanin content was lowest in the variegated pink-green leaves (Fig. 10).

\section{Discussion}

Leaf color is one of the most important traits of ornamental kale. Pink-leaved ornamental kale with green variegation is a unique material for exploring the molecular mechanism of leaf color formation. In this study, we used RNA sequencing to analyze the expression patterns of DEGs involved in anthocyanin and carotenoid

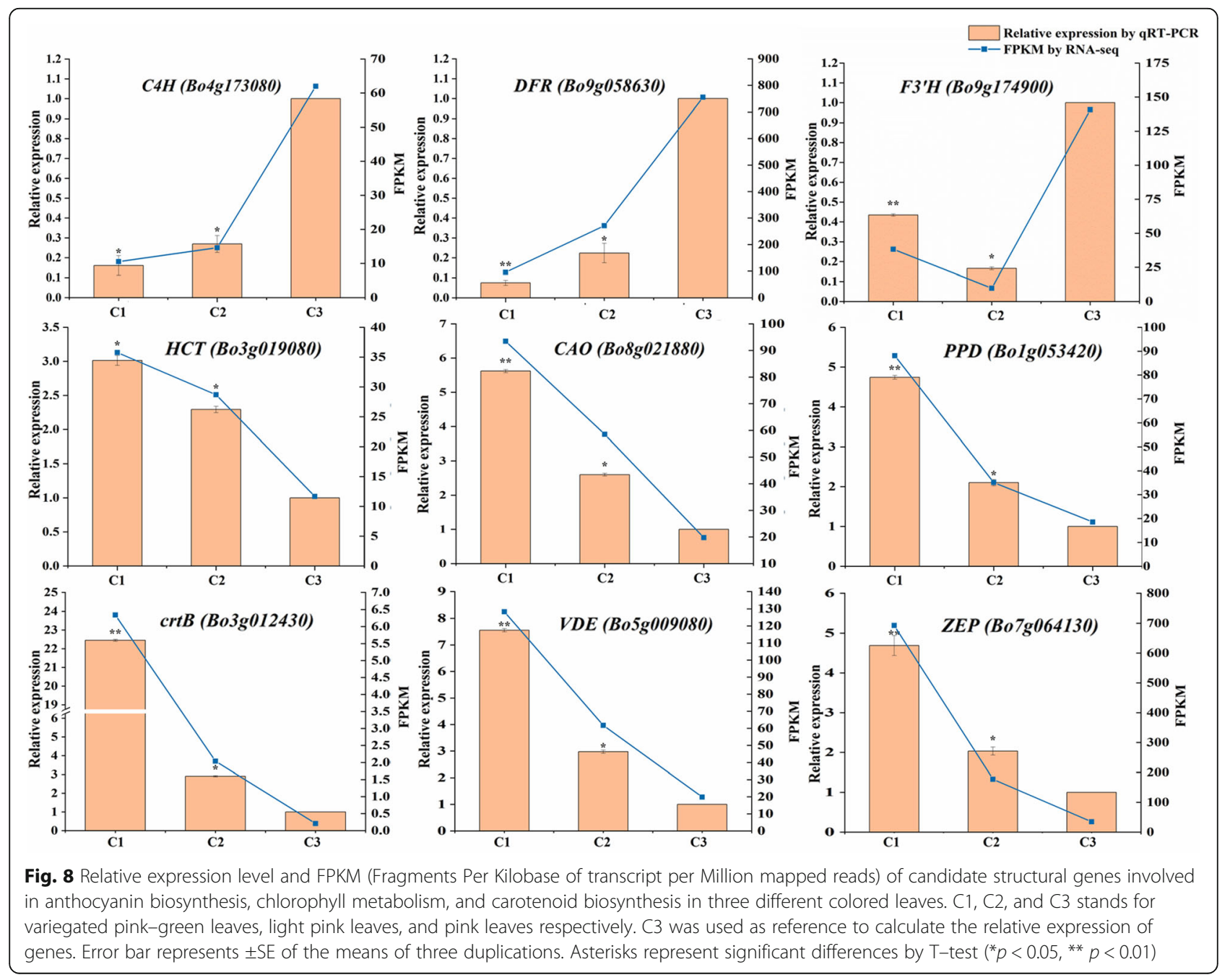




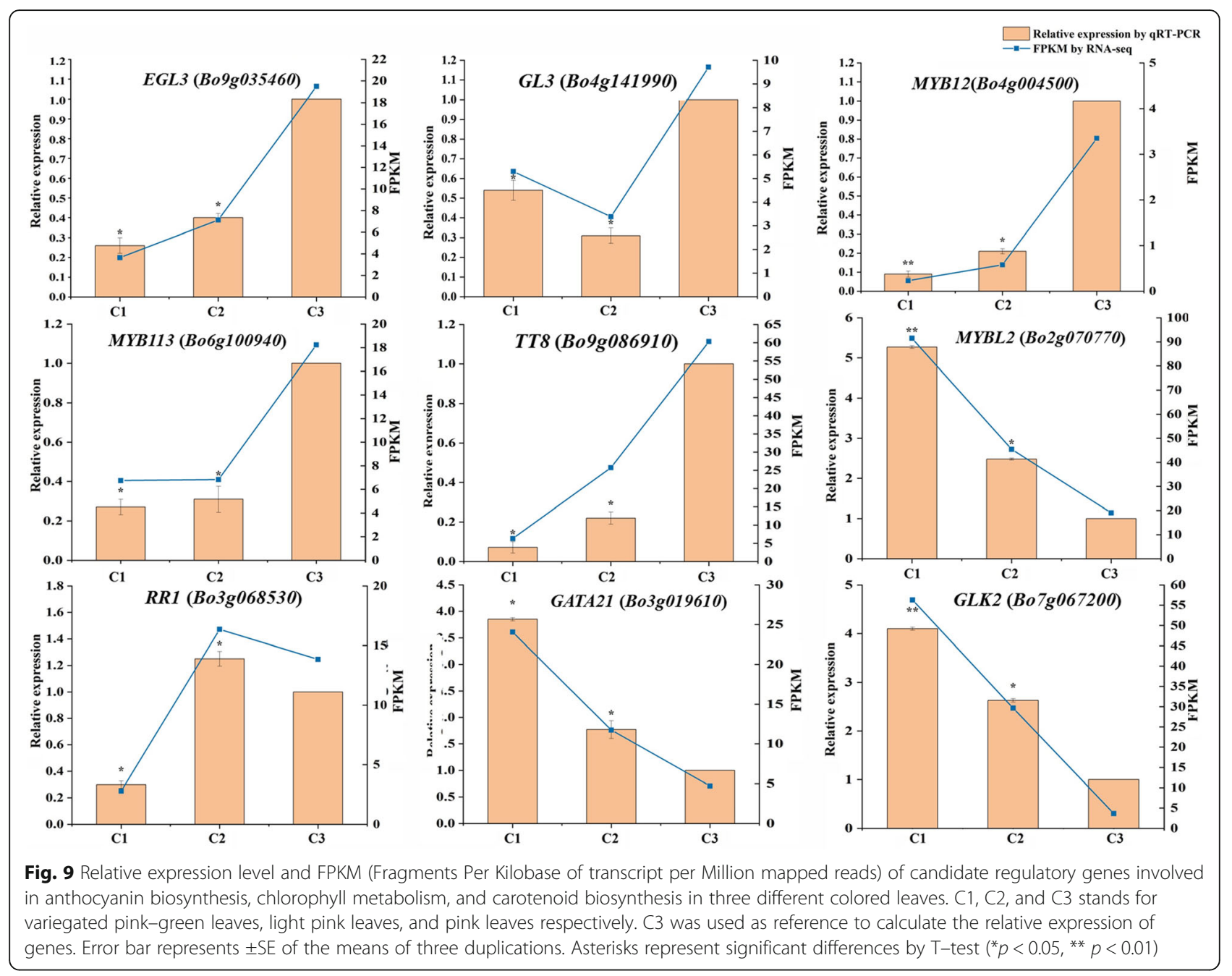

biosynthesis, and chlorophyll metabolism, in different colored ornamental kale leaves. The contents of anthocyanin, chlorophyll, and carotenoids were analyzed in parallel. The results revealed the relationship between differences in gene expression and the variation of pigment contents, allowing us to identify candidate genes involved in pigment biosynthesis and metabolism.

\section{Differential expression of genes related to anthocyanin biosynthesis}

In recent years, transcriptome sequencing technology has been widely used to identify candidate genes and analyze gene expression because of its low cost and high throughput [33]. A previous comparative transcriptome analysis identified 81 anthocyanin biosynthetic genes in the $B$. oleracea reference genome. Of these genes, BoDFR1, BoANS, and BoUGT79B1.1, BoTTG1, BoTT8, BoMYBL2.1, BoTT19.1, and BoTT19.2 are important for determining red versus white pigmentation in ornamental kale [28]. LBD39, LBD37, and $\mathrm{C} 4 \mathrm{H}$ were associated with anthocyanin biosynthesis in bicolor ornamental kale [29]. BoC4H2, BoUGT9, and BoGST21 have been proposed as key genes for anthocyanin biosynthesis in purple ornamental kale compared with white [30]. A comparative analysis of purple and green ornamental kale identified 46 DEGs involved in anthocyanin biosynthesis, of which 45 were upregulated in purple leaves [30].

In the current study, 15 DEGs related to anthocyanin biosynthesis were detected in three pairwise comparisons of different colored leaves of the 'Pink 42' cultivar of ornamental kale. It was noted that all of the DEGs related to earlier anthocyanin biosynthesis in the $\mathrm{C} 1$ (variegated pink-green leaves) versus $\mathrm{C} 2$ (light pink leaves) comparison ( $P A L, B o 5 g 137560$; 4CL, Bo9g076260; F3' $H$, Bo9g174900) were upregulated in $\mathrm{C} 2$, but anthocyanin content was lower in $\mathrm{C} 2$ than in $\mathrm{C} 1$. Because the expression pattern of these genes is contrary to the trend in pigment variation, we can infer that they are not key genes for controlling anthocyanin biosynthesis. Liu et al. identified Bo9g058630, which is homologous to AT5G42800 


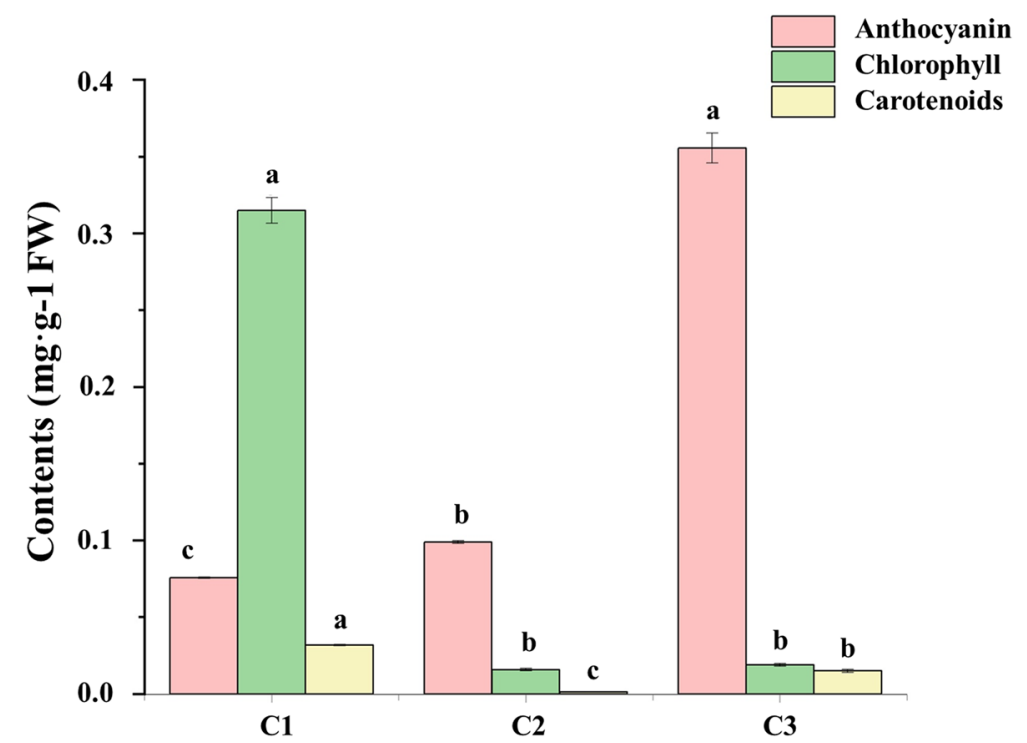

Fig. 10 Anthocyanin, chlorophyll, and carotenoid contents in different colored leaves of 'Pink 42'. C1, C2, and C3 stands for variegated pinkgreen leaves, light pink leaves, and pink leaves, respectively. Different letters indicate statistically significant differences in the contents of the same pigment among different leaf types $(p<0.05)$ based on the analysis of variance (ANOVA) (Tukey test)

$(D F R)$, the structural gene for dihydroflavonol 4-reductase, as a key gene for anthocyanin biosynthesis in ornamental kale [26]. Similar results were reported by Ren et al. [27]. Cinnamic acid-4-hydroxylase $(\mathrm{C} 4 H)$, a key enzyme in phenylpropanoid biosynthesis, affects the early steps of anthocyanin biosynthesis. In our comparison of variegated pink-green leaves (C1) with pink leaves (C3), DFR (Bo9g058680) was the most downregulated DEG in C1. In C2 (light pink) versus C3 (pink), C4H (Bo4g173080) was the most downregulated DEG. We got similar results in qRT-PCR test. These results indicate that decreased expression of DFR (Bo9g058680) and C4H (Bo4g173080) results in decreased anthocyanin content as leaves develop.

Our study also revealed a branched pathway for anthocyanin biosynthesis. Unlike the pathway reported previously, this one synthesizes anthocyanin through the formation of caffeoyl-CoA from p-coumaroyl CoA by the action of shikimate $\mathrm{O}$-hydroxycinnamoyltransferase $(H C T)$, followed by steps catalyzed by enzymes encoded by $C H S, F 3 H, D F R$, and ANS. In A. thaliana, HCT is a lignin biosynthetic gene. Silencing of $H C T$ in plants inhibits lignin biosynthesis, leading to activation of $\mathrm{CHS}$ and the accumulation of several flavonol glycosides and acylated anthocyanin [34]. In the current study, HCT (Bo3g019080) was detected as a DEG in comparisons between $\mathrm{C} 1$ versus $\mathrm{C} 3$ and $\mathrm{C} 2$ versus $\mathrm{C} 3$. Furthermore, the expression of $H C T$ was downregulated in $\mathrm{C} 3$ compared with both $\mathrm{C} 1$ and $\mathrm{C} 2$, indicating that anthocyanin accumulation is associated with downregulation of $H C T$ (Bo3g019080) in ornamental kale.

\section{DEGs related to chlorophyll metabolism and carotenoid biosynthesis}

Previously, it was shown that decreasing chlorophyll content in triple-color ornamental kale leaves is caused by chlorophyll biosynthesis inhibition [24]. In our comparisons of $\mathrm{C} 1$ versus $\mathrm{C} 2$ and $\mathrm{C} 2$ versus $\mathrm{C} 3$, all DEGs related to chlorophyll metabolism, including chlorophyll biosynthesis, chlorophyll cycle, and chlorophyll degradation, were upregulated in $\mathrm{C} 2$ compared with $\mathrm{C} 1$ and $\mathrm{C} 3$ compared with $\mathrm{C} 2$. This result indicates that both chlorophyll biosynthesis and degradation are upregulated in the transition from pink to variegated pinkgreen leaf pigmentation. This is contrary to our expectation that an increased rate of biosynthesis and a decreased rate of degradation would be responsible for the accumulation of chlorophyll. CAO (Bo8g021880), a DEG related to chlorophyll cycle, was identified in three comparisons. The expression of gene $C A O$ was upregulated during the pink leaves changed to the variegated pink-green revealed through qRT-PCR experiment. PPD (Bo1g053420), which is related to chlorophyll degradation, was not only identified as a DEG in all three comparisons, but also showed the biggest differences in expression level among the DEGs. We could infer that genes $C A O$ and $P P D$ may play important roles in chlorophyll metabolism in ornamental kale. VDE (Bo5g009080) and ZEP (Bo7g064130), which are related to carotenoid biosynthesis, were also detected as DEGs across all three comparisons. In addition, crtB (Bo3g012430), another carotenoid biosynthesis gene, showed the highest expression in variegated pink-green leaves relative to the other 
samples. These results suggest that carotenoid biosynthesis might be closely related to the expression of $V D E$ (Bo5g009080), ZEP (Bo7g064130), and crtB (Bo3g012430) in ornamental kale leaves.

\section{Leaf color is closely related to pigment content}

Anthocyanins, chlorophyll, and carotenoids are important pigments in ornamental kale. The concentration ratios of these pigments strongly influence the color of kale leaves [25]. As pink leaves became light pink, the anthocyanin and carotenoid contents declined, while the chlorophyll content decreased slightly, but not significantly. As light pink leaves subsequently became variegated pink-green, the anthocyanin content was continued to decline, while the chlorophyll and carotenoid contents increased, ultimately producing green variegation. As the leaves developed, chlorophyll and carotenoids were first degraded and then accumulated. The simultaneous increase in chlorophyll and decrease anthocyanin leads to the formation of variegated pink-green leaves.

\section{Conclusions}

In this study, transcriptome sequencing and pigment content analysis revealed that DEGs involved in anthocyanin biosynthesis were downregulated in light pink leaves (C2) compared with pink leaves (C3), while anthocyanin content was lower in C3 than C2 leaves. Similar results were obtained in the $\mathrm{C} 2$ versus $\mathrm{C} 1$ (variegated pink-green) comparison. In addition, DEGs involved in chlorophyll metabolism and carotenoid biosynthesis were upregulated in C1 compared with C3, while chlorophyll and carotenoid contents were increased in C3 compared with $\mathrm{C} 1$. We propose that the changes in leaf color from pink to light pink to light pink with green variegation are caused by continuous anthocyanin degradation and chlorophyll accumulation, along with the successive degradation and accumulation of carotenoid (Fig. 11). These findings provide a basis for exploring the molecular mechanism of variegation and color development in ornamental kale leaves.

\section{Methods}

Plant materials

Fresh leaves from the rosette stage of ornamental kale (Brassica oleracea var. acephala DC) cultivar 'Pink 42' were used for RNA sequencing, qRT-PCR experiment, and pigment content analysis. All experimental materials were cultivated in a greenhouse at $25^{\circ} \mathrm{C} \pm 3{ }^{\circ} \mathrm{C}$ under a $16 \mathrm{~h}$ light $/ 8 \mathrm{~h}$ dark photoperiod at Shenyang Agricultural University, Shenyang, China, in 2019. The variegated pink-green leaves were named $\mathrm{C} 1$, the light pink leaves C2, and the pink leaves C3 (Fig. 1). Three independent biological replicates were conducted for each experiment. The ornamental kale cultivar 'Pink 42' used in the current study was identified by Prof. Pengfang Zhu. It is stored in the Shenyang Agricultural University Ornamental Kale

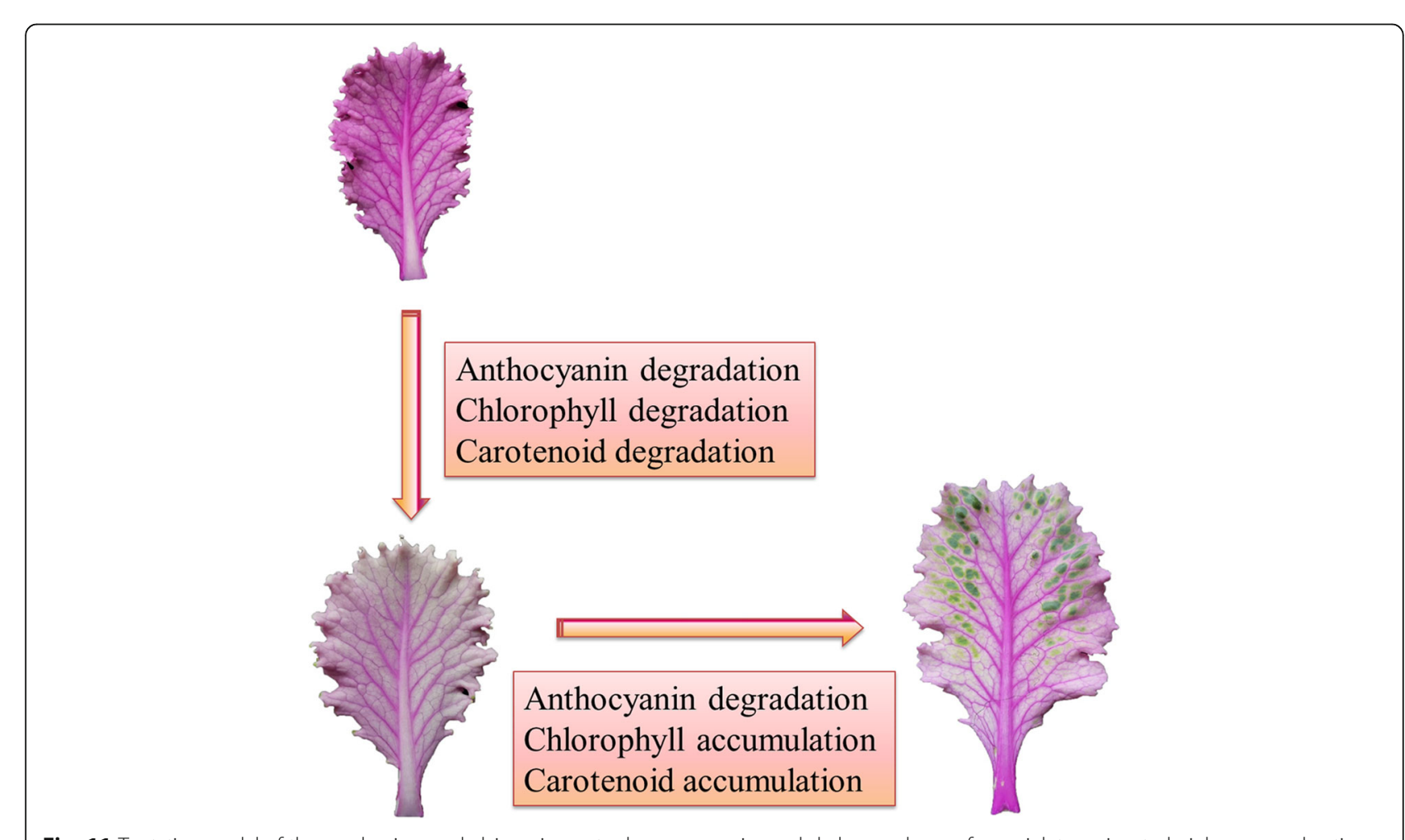

Fig. 11 Tentative model of the mechanism underlying pigments change occurring as kale leaves change from pink to variegated pink-green coloration 
Germplasm Garden. The plant materials are available from the corresponding author on reasonable requests.

\section{RNA extraction}

Total RNA was extracted using RNAiso reagent (TaKaRa, Japan), according to the manufacturer's instructions. The quality and purity of the extracted RNA were measured with an agarose gel and NanoDrop 8000 spectrophotometer (Thermo Scientific, USA). RNA integrity was evaluated using a 2100 Bioanalyzer RNA Nano chip device (Agilent, USA).

\section{Library construction and sequencing}

The Arraystar Seq-Star ${ }^{\text {Ts }}$ Rapid RNA-seq Kit (Illumina) was used to construct cDNA libraries according to the manufacturer's instructions. Briefly, total RNA was purified and fragmented, and the random N6 primers were reverse-transcribed for first-strand biosynthesis. Then, the cDNA double strand was synthesized to form double-stranded DNA using DNA polymerase I and RNase H. The doublestranded DNA was used as a template for PCR amplification to construct the final DNA library. Finally, the cDNA libraries were sequenced on the Illumina HiSeqTM 2000 platform (Gooalgene Technology Co., Ltd., Wuhan, China).

\section{RNA sequencing and data analysis}

Sequencing data (raw reads) containing joints, reads with unknown bases $N>10 \%$, and reads of low quality, were filtered with fastp (https://github.com/OpenGene/fastp) [31]. Filtered clean reads were then aligned to the $B$. oleracea reference genome (http://plants.ensembl.org/ Brassica_oleracea/Info/Index) using HISAT [35]. DEGs were detected using DEGseq2. We identified DEGs with a fold-change of two or more, and a Q-value of $\leq 0.05$ $[32,36]$. Gene functional annotation, classification and pathway enrichment analysis were performed using Gene Ontolog (http://geneontology.org/docs/ontologydocumentation/) and the Kyoto Encyclopedia of Genes and Genomes (KEGG) (https://www.kegg.jp/kegg/ pathway.html). Enrichment analysis and the determination of $P$-values were carried out using the phyper function in $\mathrm{R}$, with subsequent false discovery rate (FDR) correction for the $P$-value. A $Q$-value of $<0.05$ was considered a significant enrichment.

\section{qRT-PCR validation of candidate gene expression}

To verify the reliability of the RNA-seq results, nine candidate genes were selected for Quantitative Real-time PCR analysis, including four anthocyanin biosynthesis genes (C4H, Bo4g173080; F3'H, Bo9g174900; DFR, Bo9g058630; and HCT, Bo3g019080), two chlorophyll metabolism genes (PPD, Bolg053420; and CAO, Bo8gO 21880 ), and three carotenoid biosynthesis genes ( $V D E$, Bo5g009080; ZEP, Bo7g064130; and crtB, Bo3g012430).
The gene BoACTIN (Bo5g117040) was used as an internal control. C3 was used as reference to calculate the relative expression of genes. Quantitative Real-time PCR was performed in a total volume of $20 \mu \mathrm{L}$ reaction system containing $10 \mu \mathrm{L} 2 \mathrm{~TB}$ Green Premix Ex Taq II (Takara, Dalian, China), 0.4 $\mu \mathrm{L} 50$ ROX Reference Dye, $2 \mu \mathrm{L}$ of 50 $\mathrm{ng} / \mu \mathrm{L} \quad \mathrm{cDNA}, 1 \mu \mathrm{L}$ of $10 \mu \mathrm{M}$ gene-specific primer (Additional file 2: Table S3), and 5.6 $\mathrm{L}$ RNase-free water. The reaction conditions were set at $95^{\circ} \mathrm{C}$ for $30 \mathrm{~s}, 40 \mathrm{cy}$ cles of $95^{\circ} \mathrm{C}$ for $5 \mathrm{~s}, 60^{\circ} \mathrm{C}$ for $30 \mathrm{~s}$. The data were analyzed using StepOnePlus Real-Time PCR System (Applied Biosystems, America). Three independent biological and technical replicates were conducted for each experiment. The relative expression levels of the candidate genes were determined using the $2^{-\Delta \Delta C T}$ method [37].

\section{Determination of anthocyanin, chlorophyll, and carotenoid contents}

Anthocyanin, chlorophyll, and carotenoid contents were extracted and determined as previously described [25].

Briefly, anthocyanin content was determined as follows. Fresh leaf samples $(2.0 \mathrm{~g})$ were added to $30 \mathrm{~mL}$ of extraction solution $(0.1 \mathrm{~mol} / \mathrm{L} \mathrm{HCl}, 95 \%$ ethanol =1: 1$)$. Samples were extracted in a water bath at $60^{\circ} \mathrm{C}$ for $1 \mathrm{~h}$, centrifuged at $5000 \mathrm{rpm} / \mathrm{min}$ at $4{ }^{\circ} \mathrm{C}$ for $15 \mathrm{~min}$, and then the supernatant was collected. Two $1-\mathrm{mL}$ aliquots of anthocyanin were collected, added to $2 \mathrm{~mL}$ of $1 \mathrm{~mol} / \mathrm{L}$ $\mathrm{KCl}$ buffer at $\mathrm{pH} 1.0$ and $2 \mathrm{~mL}$ of $1 \mathrm{~mol} / \mathrm{L}$ sodium acetate buffer at $\mathrm{pH} 4.0$, and shaken well. The absorbance value at $520 \mathrm{~nm}$ and $700 \mathrm{~nm}$ was determined. Three independent technical replicates were conducted for all the experiments. Anthocyanin content was determined using the following equations:

$$
\begin{gathered}
\mathrm{A}=(\mathrm{A} 520-\mathrm{A} 700) \mathrm{pH} 1.0-(\mathrm{A} 520-\mathrm{A} 700) \mathrm{pH} 4.5 \\
\mathrm{C}(\mathrm{mg} \cdot \mathrm{g}-1)=\frac{A \times V \times n \times M}{\varepsilon \times m}
\end{gathered}
$$

A, the difference of the absorbance value at $\mathrm{pH} 1.0$ and $\mathrm{pH} 4.5$ under $520 \mathrm{~nm}$ and $700 \mathrm{~nm}$; V, total volume of extract $(\mathrm{mL}) ; \mathrm{n}$ : dilution time; $\mathrm{M}$, the molecular mass of cyanidin-3-glucoside chloride (449.2); $\varepsilon$, the molar absorptivity of cy-3-glu (26,900); m, sample quality (g).

Chlorophyll and carotenoid content were determined as follows. Fresh leaf samples $(0.5 \mathrm{~g})$ were rapidly ground to homogeneity in $2-3 \mathrm{~mL} 95 \%$ ethanol. Then, $10 \mathrm{~mL}$ 95\% ethanol was added and the sample was further ground to a pulp before being left aside for 3-5 min. The extract was filtered into a brown volumetric bottle, and diluted to $15 \mathrm{~mL}$ with $95 \%$ ethanol. Absorbance values were measured at 665,649 , and $470 \mathrm{~nm}$, with $95 \%$ ethanol used as a blank. Three independent technical replicates were conducted for each experiment. The following equations were used to determine chlorophyll and carotenoid contents: 


$$
\begin{gathered}
\mathrm{Cchl}=\mathrm{Ca}+\mathrm{Cb} \\
\text { Chlorophyll } a \text { content }\left(\mathrm{mg} \cdot \mathrm{g}^{-1} \mathrm{FW}\right)=13.95 \mathrm{~A} 665 \mathrm{~nm}-6.88 \mathrm{~A} 649 \mathrm{~nm} \\
\text { Chlorophyll } b \text { content }\left(\mathrm{mg} \cdot \mathrm{g}^{-1} \mathrm{FW}\right)=24.96 \mathrm{~A} 649 \mathrm{~nm}-7.32 \mathrm{~A} 665 \mathrm{~nm} \\
\text { Total chlorophyll content }\left(\mathrm{mg} \cdot \mathrm{g}^{-1} \mathrm{FW}\right)=\mathrm{C}\left(\mathrm{mg} \cdot \mathrm{g}^{-1}\right)=(\mathrm{Cchl} \times \mathrm{V} \times \mathrm{n}) / \mathrm{m} \\
\text { Carotenoid content }\left(\mathrm{mg} \cdot \mathrm{g}^{-1} \mathrm{FW}\right)=\mathrm{C}\left(\mathrm{mg} \cdot \mathrm{g}^{-1}\right)=\frac{\left(1000 \times A_{470}-2.05 \times C_{a}-114.8 \times C_{b}\right) \times V \times n}{245 \times m}
\end{gathered}
$$

$\mathrm{C}_{a}$, chlorophyll $\mathrm{a} ; \mathrm{C}_{b}$, chlorophyll $\mathrm{b} ; \mathrm{V}$, total volume of extract $(\mathrm{mL}) ; \mathrm{n}$, dilution time; $\mathrm{m}$, sample weight $(\mathrm{g})$.

\section{Statistical analyses}

The results represent the means \pm SE of three replicates. Statistical analyses were performed using the software IBM SPSS Statistics 23.0 (https://www.ibm. com/docs/en/spss-statistics/23.0.0). The data of qRTPCR and pigment content analysis were compared by T-test and ANOVA (Tukey test), respectively. A $p$ value less than 0.05 was considered statistically significant.

\begin{abstract}
Abbreviations
DFR: Dihydroflavonol-4 reductase; HCT: Shikimate O-

hydroxycinnamoyltransferase; PPD: Pheophorbidase; crtB: 15-cis-phytoene synthase; PAL: Phenylalanine ammonia-lyase; CHS: Chalcone synthase; ANS: Anthocyanin synthase; MYB: Myeloblastosis; PIF3: Phytochrome interacting factor 3; HY5: Elongated hypocptyl 5; HemA: Glutamyl-tRNA reductase; FLU: Fluorescent in blue light; MEP: 2-C-methyl-D-erythritol-4-phosphate; MVA: Mevalonate; PSY: Phytoene synthase; CRTISO: Carotenoid isomerase; $\varepsilon-$ LCY: Epsilon lycopene cyclase; LCYE: Lycopene epsilon cyclase; CCD: Carotenoid cleavage dioxygenase; ZDS: Carotene desaturase; bHLH: Basic helix-loop-helix protein; WD40: WD40 repeat-containing protein; TTG1: Transparent testa glabra1; TT8: Transparent testa 8; MYBL2: MYB-like 2; TT19: Transparent testa 19; C4H: Cinnamate-4-hydroxylase; TR1: Transport inhibitor response 1; LBD39: Lateral organ boundaries domain 39; NAC: No apical meristem; WRKY: WRKY DNA-binding protein; UGT: UDP-glucuronosyltransferase; GST: Glutathione S-transferase; CRD: Beta 1, 3 glucan synthase catalytic subunit; PORC: Protochlorophyllide oxidoreductase C; CAO: Chlorophyll a oxygenase; CLH: Chlorophyllase; PAL: Phe-ammonia lyase; 4CL: 4coumarate:CoA ligase; CHI: Chalcone isomerase; F3'H: Flavonoid 30-hydroxylase; F3H: Flavanone 3-hydroxylase; CPOX: Coproporphyrinogen-III oxidase; ChIH: A subunit of Mg-chelatase; NOL: Chlorophyll b reducatase; RCCR: Red chlorophyll catabolite reductase; HemN: Oxygen-independent coproporphyrinogen III oxidase; chIM: Magnesium-protoporphyrin O-methyltransferase; chlE: Magnesiumprotoporphyrin IX monomethyl ester (oxidative) cyclase; por. Protochlorophyllide reductase; HCAR: 7-hydroxymethyl chlorophyll a reductase; PAO: Pheophorbide a oxygenase; HemD: Uroporphyrinogen-IIl synthase; HemE: Uroporphyrinogen decarboxylase; HemY: Protoporphyrinogen/coproporphyrinogen III oxidase; DVR: Divinyl chlorophyllide a 8-vinyl-reductase; ch/G: Chlorophyll a synthase; ZEP: Zeaxanthin epoxidase; VDE: Violaxanthin de-epoxidase; NCED: 9-cisepoxycarotenoid dioxygenase; PDS: 15-cis-phytoene desaturase; ZDS: Zeta-carotene desaturase; lcyB: Lycopene beta-cyclase; crtZ: Beta-carotene 3-hydroxylase; crth: Prolycopene isomerase
\end{abstract}

\section{Supplementary Information}

The online version contains supplementary material available at https://doi. org/10.1186/s12864-021-07785-x.

Additional file 1: Table S1. Transcription factors (TFs) in C2 versus C3. Table S2. Transcription factors (TFs) in C1 versus C2.

Additional file 2: Table S3. List of gene-specific primers used for qRTPCR test.

\section{Acknowledgements}

The authors are grateful to the National Natural Science Foundation of China (31770739) for supporting this research.

\section{Authors' contributions}

P. Z., X. F., and Y. L. designed the experiments; Y. L. performed RNA-seq data analysis, determined the contents of pigments, and drafted the manuscript; $X$. F. conducted the phenotypes assessment. Y. Z. conducted a phenotypic investigation. X. F., and F. Z. reviewed the draft. P. Z. conceived and supervised the work, and modified the manuscript. All of the authors have read and approved the final manuscript.

\section{Funding}

This research was funded by the National Natural Science Foundation of China (31770739).

\section{Availability of data and materials}

The datasets generated and/ or analysed during the current study were mostly included in this article.

The reference genomes of $B$. oleracea are available from EnsemblPlants genome database (http://plants.ensembl.org/Brassica_oleracea/Info/Index) and Bolbase (http://ocri-genomics.org/bolbase/).

The plant materials and the raw RNA-seq data during the current study are available from the corresponding author on reasonable requests.

The datasets supporting the conclusions of this article are included within the article (and its additional file).

\section{Declarations}

Ethics approval and consent to participate

Not applicable.

\section{Consent for publication}

Not applicable.

\section{Competing interests}

The authors declare that they have no competing interests.

Received: 8 February 2021 Accepted: 4 June 2021

Published online: 17 June 2021

References

1. Tanaka, Sasaki, Ohmiya. Biosynthesis of plant pigments: anthocyanins, betalains and carotenoids. Plant J. 2008;54(4):733-49. https://doi.org/1 0.1111/j.1365-313X.2008.03447.X.

2. Kähkönen HP, Heinonen M. Antioxidant activity of anthocyanins and their aglycons. J Agric Food Chem. 2003;51(3):628-33. https://doi.org/1 $0.1021 /$ ff025551i.

3. Watanabe MM, Takeda Y, Sasa T, Inouye I, Suda S, Sawaguchi T, et al. A green dinoflagellate with chlorophylls a and b: morphology, fine structure of the chloroplast and chlorophyll composition. J Phycol. 1987;23(s2):382-9. https://doi.org/10.1111/j.1529-8817.1987.tb04148.x.

4. Demmig-Adams B, Gilmore AM, Adams WW 3rd. Carotenoids 3: in vivo function of carotenoids in higher plants. FASEB J. 1996;10(4):403-12.

5. Gonzalez A, Zhao M, Leavitt JM, et al. Regulation of the anthocyanin biosynthetic pathway by the TTG1/ bHLH/ MYB transcriptional complex in Arabidopsis seedlings. Plant J. 2010;53(5):814-27.

6. Martens S, Preu A, Matern U. Multifunctional flavonoid dioxygenases: flavonol and anthocyanin biosynthesis in Arabidopsis thaliana L. Phytochemistry. 2010;71(10):1040-9. https://doi.org/10.1016/j.phytochem.201 0.04.016.

7. Liu Y, Lin-Wang K, Deng C, et al. Comparative transcriptome analysis of white and purple potato to identify genes involved in anthocyanin biosynthesis. PLoS One. 2015;10(6):e0129148. 
8. Takos AM, Jaffé FW, Jacob SR, et al. Light-induced expression of a MYB gene regulates anthocyanin biosynthesis in red apples. Plant Physiol. 2018; 142(3):1216-32.

9. Shin J, Park E, Choi G. PIF3 regulates anthocyanin biosynthesis in an HY5dependent manner with both factors directly binding anthocyanin biosynthetic gene promoters in Arabidopsis. Plant J. 2007;49(6):981-94. https://doi.org/10.1111/j.1365-313X.2006.03021.x.

10. Jie Z, Jin-Jun Z, Ying-Ying W, et al. Positive regulation of phytochrome $B$ on chlorophyll biosynthesis and chloroplast development in rice. Rice Sci. 2013; 04:243-8.

11. Zhang K, Liu Z, Shan X, et al. Physiological properties and chlorophyll biosynthesis in a Pak-choi (Brassica rapa L. ssp. chinensis) yellow leaf mutant, pylm. Acta Physiol Plant. 2017;39(1):1-10

12. Xiangjun Z, Zhangjun F, Thannhauser TW, et al. Transcriptome analysis of ectopic chloroplast development in green curd cauliflower (Brassica oleracea L. var. botrytis). BMC Plant Biol. 2011;11(1):169.

13. Yan-Wen W, Si-Ming C, Wei-Jie W, et al. The DnaJ-Like zinc finger domain protein PSA2 affects light acclimation and chloroplast development in Arabidopsis thaliana. Front Plant Sci. 2016;24(7):360.

14. Liu X, Chen CY, Wang KC, Luo M, Tai R, Yuan L, et al. PHYTOCHROME INTE RACTING FACTOR3 associates with the histone deacetylase HDA15 in repression of chlorophyll biosynthesis and photosynthesis in etiolated Arabidopsis seedlings. Plant Cell. 2013;25(4):1258-73. https://doi.org/10.1105/ tpc.113.109710.

15. Zeng Z, Lin T, Zhao J, et al. OsHemA gene, encoding glutamyl-tRNA reductase (GluTR) is essential for chlorophyll biosynthesis in rice (Oryza sativa). J Integr Agric. 2020;19(03):16-27.

16. Meskauskiene R, Nater M, Goslings D, Kessler F, op den Camp R, Apel K. FLU: a negative regulator of chlorophyll biosynthesis in Arabidopsis thaliana. Proc Natl Acad Sci. 2001;98(22):12826-31. https://doi.org/10.1073/pnas.221252798.

17. Ha SH, Kim JB, Park JS, et al. Carotenoids biosynthesis and their metabolic engineering in plants. Korean J Plant Biotechnol. 2003;30(1):81-95.

18. Tian H, Fang L, Zhang Q, et al. Transcriptome analysis of carotenoid biosynthesis in the Brassica campestris L. subsp. chinensis var. rosularis Tsen. Sci Hortic. 2018;235:116-23. https://doi.org/10.1016/j.scienta.2018.02.040.

19. Rodríguez-Villalón A, Gas E, Rodríguez-Concepción M. Phytoene synthase activity controls the biosynthesis of carotenoids and the supply of their metabolic precursors in dark-grown Arabidopsis seedlings. Plant J. 2010; 60(3):424-35.

20. Hao Z, Liu S, Hu L, et al. Transcriptome analysis and metabolic profiling reveal the key role of carotenoids in the petal coloration of Liriodendron tulipifera. Hortic Res. 2020;1(7):70.

21. Zhang J, Li H, Zhang M, Hui M, Wang Q, Li L, et al. Fine mapping and identification of candidate $\mathrm{Br}$-or gene controlling orange head of Chinese cabbage (Brassica rapa L. ssp. pekinensis). Mol Breed. 2013;32(4):799-805. https://doi.org/10.1007/s11032-013-9907-z.

22. Fraser PD, Kiano JW, Shipton CA, et al. Elevation of carotenoids in tomato by genetic manipulation. J Sci Food Agric. 2001;81(9):822-7. https://doi. org/10.1002/jsfa.908.

23. Feng $X$, Zhang $Y$, Wang $H$, Tian Z, Xin S, Zhu P. The dihydroflavonol 4reductase BoDFR1 drives anthocyanin accumulation in pinkish leaved ornamental kale. Theor Appl Genet. 2020;134(1):159-69. https://doi.org/10.1 007/s00122-020-03688-9.

24. Liu X, Zhang B, Wu J, Li Z, Han F, Fang Z, et al. Pigment variation and transcriptional response of the pigment synthesis pathway in the $\$ 2309$ triple-color ornamental kale (Brassica oleracea L. var. acephala) line. Genomics. 2020;112(3):2658-65. https://doi.org/10.1016/j.ygeno.2020.02.019.

25. Zhu P, Tian Z, Pan Z, Feng X. Identification and quantification of anthocyanins in different coloured cultivars of ornamental kale (Brassica oleracea L. var. acephala DC). J Hortic Sci Biotechnol. 2018;93(5):466-73. https://doi.org/10.1080/14620316.2017.1413425.

26. Liu XP, Gao BZ, Han FQ, et al. Genetics and fine mapping of a purple leaf gene, BoPr, in ornamental kale (Brassica oleracea L. var. acephala). BMC Genomics. 2017:18(1):230.

27. Ren J, Liu Z, Niu R, Feng H. Mapping of Re, a gene conferring the red leaf trait in ornamental kale (Brassica oleracea L. var. acephala). Plant Breed. 2015; 134(4):494-500. https://doi.org/10.1111/pbr.12286.

28. Guo N, Han S, Zong M, Wang G, Zheng S, Liu F. Identification and differential expression analysis of anthocyanin biosynthetic genes in leaf color variants of ornamental kale. BMC Genomics. 2019;20(1):564. https://doi. org/10.1186/s12864-019-5910-z.
29. Ren J, Liu Z, Chen W, Xu H, Feng H. Anthocyanin degrading and chlorophyll accumulation lead to the formation of bicolor leaf in ornamental kale. Int J Mol Sci. 2019;20(3):603. https://doi.org/10.3390/ijms20030603.

30. Jin S, Rahim MA, Afrin KS, et al. Transcriptome profiling of two contrasting ornamental cabbage (Brassica oleracea var. acephala) lines provides insights into purple and white inner leaf pigmentation. BMC Genomics. 2018;19(1):797.

31. Chen S, Zhou Y, Chen Y, Gu J. Fastp: an ultra-fast all-in-one FASTQ preprocessor. Bioinformatics. 2018;34(17):i884-90. https://doi.org/10.1093/ bioinformatics/bty560.

32. Love Ml, Huber W, Anders S. Moderated estimation of fold change and dispersion for RNA-seq data with DESeq2. Genome Biol. 2014;15(12):550. https://doi.org/10.1186/s13059-014-0550-8.

33. Wang Z, Gerstein M, Snyder M. RNA-Seq: a revolutionary tool for transcriptomics. Nat Rev Genet. 2009;10(1):57-63. https://doi.org/10.1038/ nrg2484.

34. Besseau S, Hoffmann L, Geoffroy P, Lapierre C, Pollet B, Legrand M. Flavonoid accumulation in Arabidopsis repressed in lignin synthesis affects auxin transport and plant growth. Plant Cell. 2007;19(1):148-62. https://doi. org/10.1105/tpc.106.044495.

35. Kim D, Langmead B, Salzberg SL. HISAT: a fast spliced aligner with low memory requirements. Nat Methods. 2015;12(4):357-60. https://doi.org/10.1 038/nmeth.3317.

36. Anders $\mathrm{S}$, Huber W. Differential expression analysis for sequence count data. Genome Biol. 2010;11(10):R106. https://doi.org/10.1186/gb-2010-11-10-r106.

37. Livak KJ, Schmittgen TD. Analysis of relative gene expression data using real-time quantitative $P C R$ and the $2^{-\Delta \Delta C T}$ method. Methods. 2001;25:402-8.

\section{Publisher's Note}

Springer Nature remains neutral with regard to jurisdictional claims in published maps and institutional affiliations.
Ready to submit your research? Choose BMC and benefit from:

- fast, convenient online submission

- thorough peer review by experienced researchers in your field

- rapid publication on acceptance

- support for research data, including large and complex data types

- gold Open Access which fosters wider collaboration and increased citations

- maximum visibility for your research: over 100M website views per year

At $\mathrm{BMC}$, research is always in progress.

Learn more biomedcentral.com/submissions 